\title{
SUSTAINABILITY AND THE OFFICIAL COMMUNITY PLAN: INTEGRATING COMMUNITY-BASED RESEARCH INITIATIVES INTO A STANDARDIZED TECHNICAL COMMUNICATION COURSE FOR SECOND-YEAR ENGINEERING STUDENTS
}

\author{
Berndt, A. \\ Centre for Professional Skills Development, Faculty of Applied Science \\ The University of British Columbia, Vancouver Canada \\ ayberndt@apsc.ubc.ca
}

\section{INTRODUCTION}

In-class observations suggest that engineering students in a standardized second-year technical communication course tend to remain disengaged from course content, largely viewing communication skills and social awareness as "soft skills" they will automatically "pick up on the job" after graduation. However, current ABET and new CEAB accreditation criteria state that engineering students must graduate with an ability to communicate effectively as well as an understanding of the social implications of engineering [1], [2]. This pilot project, an emerging natural experiment, suggests that engineering students at the second-year level can work towards achieving these goals through engagement in community-based research (CBR) on sustainability and possible contribution to an Official Community Plan. METHODS

Applied Science 201 (Technical Communication) is a required threecredit course for all second-year engineering students and is taught by several instructors across approximately 30 sections (up to 900 students) per academic year in the Faculty of Applied Science at the University of British Columbia. Instructors use a standardized syllabus, with the same textbook, readings, assignments, midterm and final examinations across all sections. The core assignment comprises a collaborative formal report, with the technical background report as the most commonly assigned genre. The formal report was identified as an opportunity to integrate community-based research and learning into the existing syllabus; this pilot project was implemented by one instructor (the author) in three sections/classes, with a total of 62 students, from September to December 2009.

\section{The Formal Report: The Standard and the Alternative}

Students were placed into teams on the basis of their research interests and then given an option for the collaborative formal report: (1) the standard--a technical background report on a chosen product or service related to their engineering discipline or (2) the alternative--a recommendation report on sustainability plans for a community of their choice in the province. The alternative was presented in response to the provincial government's call to the public to contribute to sustainability initiatives [3]. To prepare for the formal report, all students wrote a collaborative proposal, interviewed an expert of their choice, and wrote an individual progress report. At the end, each team gave a presentation of their formal report to the class. Of 62 students, 29 students ( 9 teams of 3-4 students) chose the alternative report. This pilot project focuses on differences in learning objectives and research/writing skills between these two groups of students.

Critical Reflections

Quantitative and qualitative data were obtained through three sets of critical reflections in memo format at relevant points in the course. Fifteen minutes were allotted to each of the three in-class critical reflections. Out-of-class qualitative data, such as individual progress reports, confidential peer evaluations, email messages to the instructor and end-of-term course evaluations, were also examined for consistency with in-class critical reflections. Critical reflections focused on (1) scope of report, (2) interview issues, and (3) learning objectives.

\section{RESULTS}

Learning objectives for the formal report were collectively determined by each class. Sixty-three percent of the students choosing the sustainability alternative reported that they exceeded their learning objectives while only $43 \%$ choosing the standard report indicated that they had exceeded them. Notably, $78 \%$ of the students in the sustainability alternative commented on the need to expand their research skills. In contrast, $18 \%$ of the students preparing the standard report commented on research skills at all and merely stated their library-based research skills were useful.

\section{DISCUSSION}

Students who chose the sustainability alternative were challenged to diversify and transfer their existing research methods from an academic to a professional context within a larger community setting directly connected to the public-sector engineering workplace. Through their online research and resulting connections with local government employees (e.g. urban planners, civil engineers), students learned about the Official Community Plan and developed a new awareness of the social, political, and financial complexity inherent in "real-life" applications of sustainability. Students also learned to consider the interview both as research instrument and as a site for social interaction [4], gaining insight into a professional Community of Practice while recognizing that building relationships is critical to the research process. Some students in the sustainability alternative regarded the interview as a key source of information that shaped their report. In contrast, students who chose the standard report tended to regard their interview with a professor as a dispensable add-on to simply confirm the information they had obtained through library and online sources.

Students in both groups demonstrated reluctance to arrange and conduct interviews with an expert of their choice. To address this reluctance, the instructor guided students in constructing emails to re/approach experts, prompting students to consider how an interview might prove useful in the research process. Most students in the sustainability alternative also demonstrated greater difficulty in narrowing the scope of their report, as the parameters of the assignment were not pre-defined, making the role of the interviews indispensable. The instructor also provided guidance through possible report organization strategies to encourage students to map out prospective areas of research based on community needs. More explicit scaffolding around report genres and pedagogical bridges from the classroom into the "real world" would have been useful to students-recommendations for further instructional development.

\section{PRELIMINARY CONCLUSIONS}

Some students suggested that the sustainability alternative be made mandatory and indicated that while the work was intensive, so was the level of engagement and motivation to work on an authentic, complex project. Facilitating connections between the classroom and the publicsector community demonstrates to engineering students that they are part of a larger socio-political context and, as "citizen engineers" [5], they will need to communicate not only with one another but also with professional and public, technical and non-technical communities.

\section{ACKNOWLEDGEMENTS}

I would like to thank Alice Cassidy, Yona Sipos, and Sarah Nyrose, who organized the first Sustainability Education Intensive at the Centre for Teaching and Academic Growth at the University of British Columbia in 2009. Without this intensive course, I would not have had the opportunity to meet Bronwyn Jarvis, who planted the seed for this pilot project.

\section{REFERENCES}

1. Applied Science Accreditation Commission, ABET, March 2010, [Online]. Available: http://www.abet.org.

2. Canadian Engineering Accreditation Board, 2009 [Online]. Available: http://www.engineerscanada.ca

3. LiveSmartBC, 2010 [Online]. Available: http://www.livesmartbc.ca/government/index.html

4. Talmy, S. Qualitative interviews in applied linguistics: From research instrument to social practice. Annual Review of Applied Linguistics 2010:30:128-48.

5. Douglas, D., Papadopoulos, G. Citizen Engineer: A handbook for socially responsible engineering. Boston: Pearson-Prentice Hall, 2010. 